Supplement of Atmos. Chem. Phys., 14, 12683-12699, 2014

http://www.atmos-chem-phys.net/14/12683/2014/

doi:10.5194/acp-14-12683-2014-supplement

(C) Author(s) 2014. CC Attribution 3.0 License.

(c) (i)

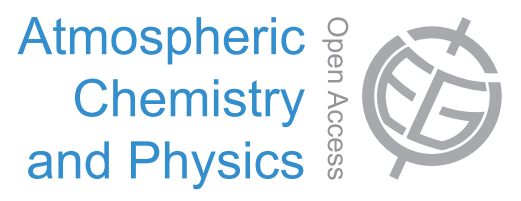

Supplement of

\title{
Atmospheric black carbon and warming effects influenced by the source and absorption enhancement in central Europe
}

S. Nordmann et al.

Correspondence to: S. Nordmann (stephan.nordmann@mpic.de) 
Table S1. Country specific emission rates of EC for the EUCAARI and BC for the Lamarque et al. (2010) emission inventory.

\begin{tabular}{lll}
\hline country & $\begin{array}{l}\text { EUCAARI EC } \\
\text { t/year }\end{array}$ & $\begin{array}{l}\text { Lamarque BC } \\
\text { t/year }\end{array}$ \\
\hline Belarus & 9817.23 & 8589.38 \\
Poland & 74140.01 & 47232.21 \\
Czech Republic & 23423.85 & 16220.78 \\
Ukraine & 101925.1 & 49637.79 \\
\hline
\end{tabular}
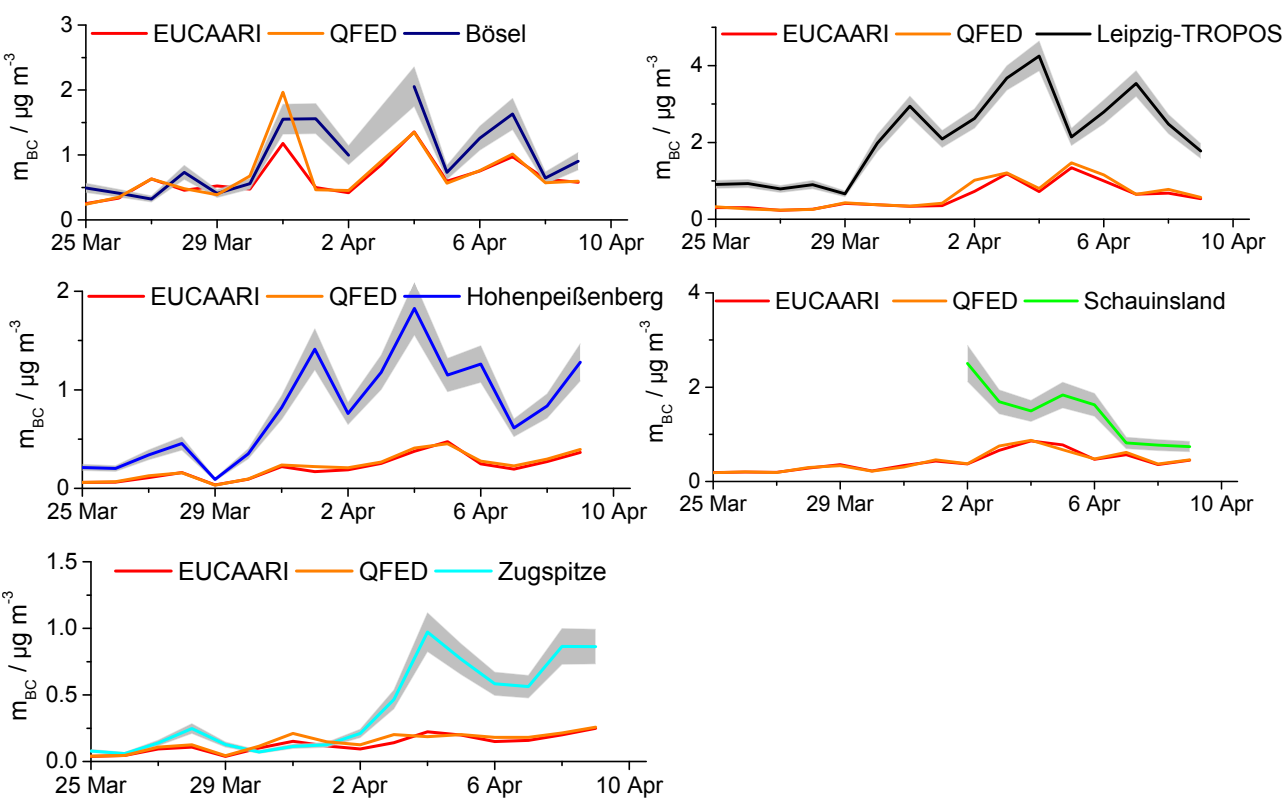

Fig. S1. Time series of modeled BC and observed $\mathrm{C}_{\text {soot }}$ mass concentrations for different observation sites. Model results for 2 different model runs are shown, base run with EUCAARI emissions and the QFED run with base EUCAARI emissions and QFED biomass burning. 


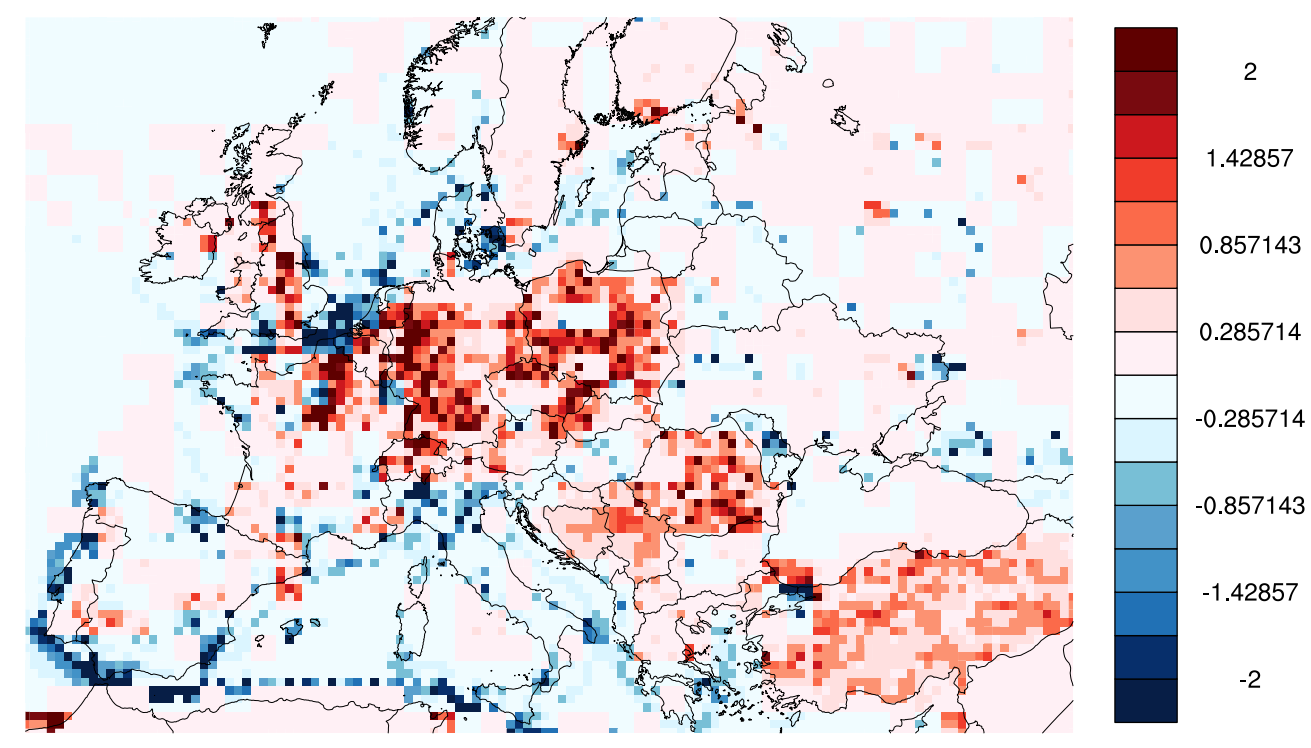

Fig. S2. Difference between EUCAARI BC emissions scaled to Arctas BC emissions and the original EUCAARI BC emissions in $n g \mathrm{~m}^{2} \mathrm{~s}^{-1}$.

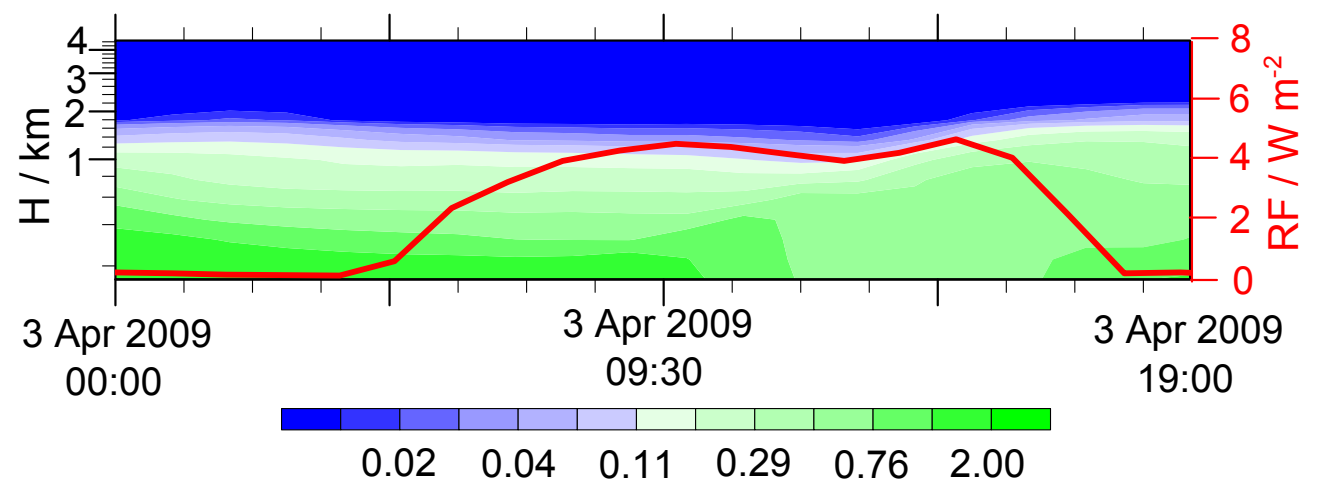

Fig. S3. Temporal evolution of the BC vertical profile for Leipzig-TROPOS and corresponding radiative forcing (RF) from model simulation. 